The Agriculturists 18(1): 66-80 (2020) ISSN 2304-7321 (Online), ISSN 1729-5211 (Print)

A Scientific Journal of Krishi Foundation

Indexed Journal

DOI: https://doi.org/10.3329/agric.v18i1.49460

\title{
Impact of Labor Migration on Rural Livelihood in Pakundia Upazila under Kishoregonj District of Bangladesh
}

\author{
Md. Safiul Islam Afrad ${ }^{1}$, Anwara Begum ${ }^{1}$, Md. Enamul Haque $^{1}$ and Noor Shaila Sarmin ${ }^{2}$ \\ ${ }^{1}$ Department of Agricultural Extension and Rural Development; and ${ }^{2}$ Department of Agro-Forestry \\ and Environment, Bangandhu Sheikh Mujibur Rahman Agricultural University, Gazipur, Bangladesh \\ *Corresponding author and Email: afrad69@gmail.com
}

Received: 26 April 2020

Accepted: 25 June 2020

\begin{abstract}
The focal objective guided the present study was to investigate the impact of labor migration on rural livelihood. Pakundia upazila under Kishoregonj district was purposively selected as the locale of the study. Three villages viz. Narandi, Hossendi and Patuabhanga were randomly selected. A sample consisting of 80 respondents, having at least one migrant agricultural labor was selected following stratified proportionate random sampling technique. Quantitative data were collected by the researchers using a structured interview schedule through face to face interview method. Qualitative data were collected through group discussion and direct observation methods. Statistics like range, mean, percentile and rank order were employed throughout the study. Majority (54.5\%) of the household owners fell under old age group; 53.2 percent belonged to the group of primary level of education; 56.3 percent had medium family; 78.8 percent families were nuclear; more than half (51.0\%) of them belonged to medium income category; greater part $(55.2 \%)$ of them had medium contact with the sources of information; 50.1 percent of the respondents had low organizational participation; and 50.0 percent of them showed high cosmopoliteness. Majority of migrant workers (46.7\%) migrated in Middle East and Dhaka city (25.3). Major causes of labor migration were higher income possibilities, job security, social status, major types of migration were rural-urban, migration to other country and seasonal migration. Vital negative impacts of labor migration on agriculture were: decreased family labor; dependency on remittance; and increased vulnerability difficult situation. Vibrant positive impacts of labor migration were observed on financial capital (increased remittance flow and total household income) followed by physical (enriched household gadgets and real properties possession), human (improved skills in agricultural practices and enhanced competency in managing farm production) and social capitals (enhanced social relation and developed social network)while negative impact was observed on natural capital (decreased agricultural land status and natural vegetation). Hiring labor, change in cropping pattern and agricultural transformation were the major ways of coping up with labor shortage in agricultural production.
\end{abstract}

Keywords: Impact, labor, migration, livelihood, rural

\section{Introduction}

Generally, migration refers to the movement of individuals from permanent residence to new residence for better settlement. Many people migrate from developing countries like Bangladesh across national boundaries for various purposes. International migration happened when people cross the boundaries of native country and stay in another host country 
for longer time (Stanat and Christensen, 2006). Migration enhances the opportunity to achieve a higher standard of health and education for the children of migrants (Islam et al., 2013).

One of the most noteworthy demographic phenomena faced by many developing countries in the world is the shortage of skilled labor and food security, and conversely the rapid population growth in the urban centers, which is largely caused by the prevalence of rural-urban migration (Agesa and Kim, 2001). Over 40.0 percent of all migrants in the world originated from Asia where population is growing faster than job opportunities (Kim et al., 2018). As economies continue to develop, the percentage of the people engaged in the agriculture sector declines. In general, 1.0 percent increase in GDP leads to decrease of 0.052 percent of people employed in agriculture (Mc Catty, 2004). Agriculture sector is also fragile from the view point of weather dependent and price stability. Respondent's welfare will be consequently affected if there is decline in the price of their crops. More farming industry just offers seasonal employment, so it does not provide suitable income to sustain the family household for an entire year (Imran et al., 2016).

Rural-urban migration is a double-edged problem affecting the rural community as well as the urban destinations. Rural community is affected because the youths and adults are supposed to remain in the community. They want to contribute to the development of agriculture in particular, and the community in general, and leave the rural areas for other destination. The 'lost labor' of able-bodied (migrated) men and women is ascribed a key role in the process of agricultural decline (Aworemi et al., 2011). According to Bureau of Manpower Employment and Training (BMET), from 1976 to 2018 , a total of $12,199,124$ Bangladeshis have migrated overseas for employment. Bangladeshi workers mainly engage in short-term contract employment; and thus, they have to return on completion of their contracts. The impact of overseas employment and concomitant remittance flow contributed significantly in the success of alleviating poverty in the country as well (Siddiqui et al., 2019).

Internal migration is associated with rural and agricultural stagnation or even decline (Regmi and Tisdell, 2002). De Haas (2001) contended that, in the long run, and after an adjustment process, agricultural decline has often been reversed through agricultural investments made possible by the inflow of remittances. De Brauw and Rozelle (2003) also provided evidence that the remittances sent home by migrants partially compensate for this lost-labor effect, contributing to household incomes directly and also indirectly by stimulating crop production. IFAD (2007) hypothesized that migration is likely to generate a positive income effect on the sending households, raising the households' ability to access important nutritional inputs like food among others. After reviewing a number of cases in Asia, Deshingkar (2004) concluded that, a loss of labor through migration may or may not reduce agricultural production, remittance may or may not increase access to assets by alleviating credit constraint: this in turn may or may not increase agricultural production and household incomes.

Out-migration results in drastic decrease in the labor which in turn reduces total cropped area and quality of work giving rise to reduced food production and reduced household wealth leading to increased vulnerability which brings about food insecurity. In view of the above circumstances, the researchers undertook the present study with specific objectives to: i) assess the socioeconomic status of household owners in the study area; ii) investigate the status of agricultural labor migration; iii) examine the impact of labor migration on agriculture rural livelihood; and iv) explore the means of coping up with the labor migration situation for adjusting agricultural production.

\section{Methodology}

Descriptive research design was applied in the present study. Pakundia upazila under 
Kishorgonj district was purposively selected as the locale of the present study. Three villages in Pakundia upazila viz. Narandi, Patuabhanga and Hossendi were selected from the upazila having high observed migration of labor. Lists 960 households having at least one migrant agricultural labor in these selected villages were collected from the respective Union Parishad Members. Stratified proportionate random sampling technique was followed in selecting 80 household head as respondent of the study. It constituted 8.33 percent of the total household heads. Another 10 family heads were kept as reserve (Table 1).

An interview schedule was prepared to collect relevant data according to the objectives of study. The instrument was pre- tested prior to the actual administration to the respondents. The pre-test was carried out on the respondents that were not part of sample of the study. Data were collected from the selected respondents using pre-tested interview schedule through face-toface interview method during October to December 2019. A group discussion was held with a group consisting of 45 members including 15 from each of these three villages to find out the destination of migrant from the study area. In addition, direct observation was made during collection of data to understand the actual situation prevailing in the villages. Appropriate scales and measurement techniques were used to ensure correct responses to the variables of concern. The independent variables considered in this study were; age, educational level, family size, family type, annual family income, savings status of the family, cosmopoliteness, contact with the sources of information and organizational participation while impact of migration on the livelihood of the respondent was the dependent variable. Collected data were compiled, coded, categorized, and analyzed in accordance with the objectives of the study. Qualitative data were converted into quantitative form by means of suitable scoring method. Descriptive statistics; viz. frequency, percentage and rank order analysis were used for presentation of results.
Age of the respondent was measured by counting years and classified into three categories according to Islam (2011). Education of the respondents was measured in formal schooling years and categorized into five categories illiterate, signature ability, primary education, secondary education and above secondary education following Tuli (2011).

The family size of the respondent was measured in number of individuals in the family including himself, his wife, children and other dependents and classified into three categories on the basis of their family size according to Parvez (2007). Types of family were classified into two categories, namely; nuclear family and joint/ extended family. Cosmopoliteness was measured in score of respondents on the basis of their visit to three different places "frequently", "occasionally", "rarely" and "not at all" and the weights assigned to these visits were ' 3 ', ' 2 ', ' 1 ' and ' 0 ', respectively following Rahman (2011).

Contact with sources of information scores of the respondents were compiled on the basis of their extent of contact with eight sources of information "frequently", "sometimes", "rarely" and "not at all" and corresponding assigned weights for each response were ' 3 ', ' 2 ', ' ' ' ' and '0', respectively following Patwary (2018). Organizational participation of the respondent was measured by membership in six different organizations and weights assigned ' 0 ' for "no participation", ' 1 ' for "not member but attend occasionally", ' 2 ' for "ordinary member", ' 3 ' for "ordinary member and attend meeting regularly" and '4' for "active member".

Respondents were classified into three categories on the basis of their organizational participation according to Sultana (2015). Annual family income of the respondents was measured in BDT on the basis of total yearly earning from agriculture and non-agriculture sources by family members was categorized into three classes according to Ali (2007). Saving status was identified by asking their opinion into three types viz. 'saving', 'no savings' and 'indebt'. 
Table 1. Distribution of the respondents in three selected villages

\begin{tabular}{cclccc}
\hline District & Upazila & Village & Total family & No. of respondent & Reserve list \\
\hline \multirow{3}{*}{ Kishoregonj } & \multirow{2}{*}{ Pakundia } & Narandi & 345 & 30 & 4 \\
& & Hossendi & 300 & 25 & 3 \\
& & Patuabhanga & 315 & 25 & 3 \\
\hline & Total & & 960 & 80 & 10 \\
\hline
\end{tabular}

Table 2. Distribution of the respondents according to their selected characteristics

\begin{tabular}{|c|c|c|c|c|c|c|c|}
\hline \multirow{2}{*}{$\begin{array}{l}\text { Variables (Unit } \\
\text { of measurement) }\end{array}$} & \multicolumn{2}{|c|}{ Score range } & \multirow[b]{2}{*}{ Categories } & \multirow[b]{2}{*}{ No. } & \multirow[b]{2}{*}{$\%$} & \multirow[b]{2}{*}{ Mean } & \multirow[b]{2}{*}{ SD } \\
\hline & Possible & Observed & & & & & \\
\hline \multirow{4}{*}{ Age (Years) } & \multirow{3}{*}{$\begin{array}{l}\text { Unkno } \\
\text { wn }\end{array}$} & \multirow{3}{*}{$28-75$} & Young (up to 35 ) & 44 & 55.0 & \multirow{3}{*}{53.9} & \multirow{3}{*}{10.2} \\
\hline & & & Middle (36 to 50 ) & 27 & 34.0 & & \\
\hline & & & Old (above 50) & 9 & 11.0 & & \\
\hline & \multirow{5}{*}{$\begin{array}{l}\text { Unkno } \\
\text { wn }\end{array}$} & \multirow{5}{*}{$0-16$} & Illiterate $(0)$ & 9 & 11.4 & \multirow{5}{*}{3.6} & \multirow{5}{*}{3.4} \\
\hline \multirow{4}{*}{$\begin{array}{l}\text { Education } \\
\text { (Schooling } \\
\text { years) }\end{array}$} & & & Can sign only (0.5) & 17 & 21.5 & & \\
\hline & & & Primary (1-5) & 42 & 53.2 & & \\
\hline & & & Secondary (6-10) & 7 & 9.0 & & \\
\hline & & & $\begin{array}{l}\text { Above secondary (above } \\
10 \text { ) }\end{array}$ & 4 & 5.1 & & \\
\hline \multirow{2}{*}{ Family type } & \multirow{2}{*}{$\begin{array}{l}\text { Nuclear } \\
\text { and joint }\end{array}$} & \multirow{2}{*}{$\begin{array}{l}\text { Nuclear } \\
\text { and joint }\end{array}$} & Nuclear family & 63 & 78.8 & \multirow{2}{*}{-} & \multirow{2}{*}{-} \\
\hline & & & Joint Family & 17 & 21.2 & & \\
\hline \multirow{3}{*}{$\begin{array}{l}\text { Family size } \\
\text { (Number) }\end{array}$} & \multirow{3}{*}{$\begin{array}{l}\text { Unkno } \\
\text { wn }\end{array}$} & \multirow{3}{*}{$3-9$} & Small $(<5)$ & 11 & 13.8 & \multirow{3}{*}{5.8} & \multirow{3}{*}{1.3} \\
\hline & & & Medium (5-7) & 45 & 56.2 & & \\
\hline & & & Large (above 7) & 24 & 30.0 & & \\
\hline \multirow{3}{*}{$\begin{array}{l}\text { Annual family } \\
\text { income (BDT) }\end{array}$} & \multirow{3}{*}{$\begin{array}{l}\text { Unkno } \\
\text { wn }\end{array}$} & \multirow{3}{*}{$\begin{array}{l}85000 \text { to } \\
366000\end{array}$} & $\begin{array}{l}\text { Low income (below } \\
130000 \text { ) }\end{array}$ & 11 & 14.2 & & \\
\hline & & & $\begin{array}{l}\text { Medium income }(130000 \\
\text { to } 200000)\end{array}$ & 42 & 51.0 & $\begin{array}{c}1512 \\
41\end{array}$ & $\begin{array}{c}6664 \\
8\end{array}$ \\
\hline & & & $\begin{array}{l}\text { High income (above } \\
200000 \text { ) }\end{array}$ & 27 & 34.8 & & \\
\hline & In debt & & Savings & 22 & 27.5 & & \\
\hline Saving status & to & - & No savings & 42 & 52.5 & - & - \\
\hline & savings & & Indebt & 16 & 20.0 & & \\
\hline & & & Low (up to 3) & 3 & 3.8 & & \\
\hline Cosmopoliteness & $0-9$ & $4-9$ & Medium (4 to 6 ) & 37 & 46.2 & 7.5 & 1.2 \\
\hline & & & High (above 6) & 40 & 50.0 & & \\
\hline Contact with the & & & Low (up to 8) & 15 & 18.9 & & \\
\hline sources of infor- & $0-24$ & $5-18$ & Medium (9 to 16$)$ & 44 & 55.2 & 13.0 & 3.1 \\
\hline mation (Score) & & & High (above 16) & 21 & 26.3 & & \\
\hline & & & Low (0 to 5) & 40 & 50.1 & & \\
\hline participation & $0-24$ & $3-20$ & Medium (6 to 9 ) & 24 & 30.2 & 9.4 & 4.5 \\
\hline & & & High (10 and above) & 16 & 20.2 & 9.4 & \\
\hline
\end{tabular}


Reasons for agricultural labor migration were computed by directly asking to mention their opinions in a four-point rating scale. The continuums of the scale were: 'no', 'low', 'moderate' and 'high' and the corresponding scores assigned to each of the continuum were ' 0 ', ' 1 ', ' 2 ', and ' 3 ', respectively. Rank order of the causes was prepared to get a comprehensive idea on the statements. Thus, a statement for 80 respondents could score a cumulative weightage of ' 0 ' to ' 240 ' where ' 0 ' would indicate 'no' cause of migration and ' 240 ' would indicate 'high' cause of migration. Based on their cumulative score of each statement, rank order of causes of labor migration was computed (Table 3). Types of labor migration from the respondents' family were measured by asking direct question. By adding the frequency of each type of family labor, rank order of labor migration type was calculated.

Impact of labor migration on rural livelihood being the dependent variable of the study was measured in terms of changes in livelihood capitals viz. human capital, physical capital, financial capital, social capital and natural capital of the rural families following DFID (1999). Change in each capital was measured computing the changes in each of two statements (Table 7). And total changes in each capital was computed adding the changes in each of two statements of each of five capitals. The respondents were asked to provide their opinions on the influence of agricultural labor migration in each of the five capital through 10 statements in four-point rating scale viz. "no change", "low change", "moderate change" and "high change". Corresponding scores of ' 0 ', ' 1 ', ' 2 ' and ' 3 ' were assigned against their responses of "low change", "moderate change" and "high change", respectively. Thus, the assigned score of each statement for 80 respondents could range from ' 0 ' to ' 240 ' where ' 0 ' would indicate 'no change' and '240' would indicate high change in their livelihood.

Coping strategy to adjust labor shortage in agricultural production was measured by asking their opinions against seven selected statements in a three-point rating scale. The continuums of the scale were: 'low', 'moderate' and 'high' against the corresponding assigned scores of ' 0 ', ' 1 ', '2', and ' 3 ', respectively. Rank order of the coping strategy statements was prepared to get a comprehensive idea on each statement. Thus, cumulative scores of a statement could range from ' 0 ' to ' 240 ' where ' 0 ' would indicate 'low' means of coping up of labor shortage and ' 240 ' would indicate 'high' means of coping up the same.

\section{Results and Discussion}

\subsection{Socioeconomic characteristics of the respondents}

Nine selected characteristics of the respondent were considered as independent variables viz. age, education, family size, family type, annual family income, saving status, cosmopoliteness, contact with sources of information and organizational participation of the respondents. It is evinced from Table 2 that majority $(54.5 \%)$ of the respondents were under old aged group as compared to 34.0 percent middle aged and 11.5 percent young aged. Therefore, more than fourfifth $(88.5 \%)$ of the respondents belonged to middle age to old age categories. Old aged respondents gradually losing their energy after these years. Middle age respondents are full of energy, having long experience and appropriate decision maker. Young aged respondents were low because they were periodic respondents and irregular. Most of the young aged respondents are engaged with other jobs like small business, poultry farming etc. Dissimilar results were reported by Imran (2011).

More than half $(53.2 \%)$ of the respondent had primary level of education whereas 21.5 percent of the respondents could sign only and 11.4 percent are illiterate. 9.0 percent belonged to the group of secondary level of education and only 5.1 percent belonged to above secondary level (Table 2). Therefore, 67.3 percent of the respondents were literate. According to UNESCO (2018), the literacy rate of Bangladesh was measured 72.8 percent. The findings 
indicate that in the study area, the literacy rate seems to be lower than that of the national level. More than half $(56.3 \%)$ of the respondents belonged to medium family group as compared to 30.1 percent large and 13.8 percent small family size. The number of medium and large family is higher and small family is lower because of lack of education and awareness (Table 2). Ali et al. (2008) found similar findings in their study but Farhad (2008) found dominancy of large to medium sized families in his studies. Among the respondent it was found that 78.8 percent family were nuclear while 21.3 percent family were joint/ extended. The dominance of nuclear family was more in the study area because different types of NGO worked there and created awareness on family planning. Contrary to the findings of this study, Ali et al. (2009) found that 42.5 percent of the respondent lived in nuclear family while 57.5 percent were joint family.

Fifty percent of the respondents were high cosmopolite while the nearly same (46.6\%) of them were moderately cosmopolite and only 3.8 percent were low cosmopolite. Therefore, almost all $(96.0 \%)$ of the respondents had medium to high level cosmopoliteness quality (Table 2). It indicates that they usually go outside their dwelling places for variety of purposes. Prodhan (2012) in a study on barriers and preparedness of Sub Assistant Agriculture Officers (SAAOs) towards ICT utilization revealed dissimilar results, i.e. 87.8 percent of the SAAOs belonged to low to medium cosmopoliteness categories.

Results contained in Table 2 mean that the greater part $(55.2 \%)$ of the respondents had medium contact with sources of information compared to 26.3 percent had high and only 18.9 percent had low contact with sources of information. Therefore, huge majority $(81.5 \%)$ of the respondents belonged to medium to high contact with the sources of information. This is the good sign among the respondents that more involvement with sources of information. This might be due to the fact that respondents are more interested in mass media which make them advance in agricultural information. Ali (2007) in his study observed that 78.0 percent of the respondents had medium contact followed by 15.0 percent low contact and only 7.0 percent had high contact with different sources of information.

It is evinced from information contained in Table 2 that 50.1 percent of the respondents had low organizational participation while 30.2 percent respondents had medium and only 20.2 percent had high organizational participation. Thus, vast majority $(80.0 \%)$ of the respondents had low organizational participation. It means that most of the respondents showed a propensity to escape from social responsibility. Afrad (2010) and Ahmed (2003) in their study found similar results regarding organizational participation.

Results displayed in Table 2 indicate that majority of the respondents $(51.0 \%)$ had medium income category and 34.8 percent and 14.2 percent had high and low-income category, respectively. Thus, very big majority of them $(85.0 \%)$ belonged to medium to large annual family income categories. This might be due to the fact that respondents are engaged with other jobs along with crop cultivation. Haider (2010) has also reported similar findings in his study.

Most of the respondents in the selected area were medium income category. They do not have much savings. The respondents who have additional income sources can save money. But the respondents who do not have any additional sources of income cannot save money. Results displayed in Table 2 indicate that more than half of the respondents $(53.0 \%)$ do not have any saving whereas 27.0 percent of the respondents have savings but 20.0 percent of the respondents are in debt. This might be due to high agricultural input cost and low profit. Moreover, respondents do not get fair price of agricultural products and especially they frequently become the victim of the situation of production boom.

\subsection{Labor migration status in the study area}

Current status of labor migration causes of labor migration, perceived impact of labor migration 
on agriculture and rural livelihood have been discussed in the following sub-heads.

\subsubsection{Causes of labor migration in the study area}

Respondent identified different causes of migration of the local labors who participated in agricultural activities. In order to understand the comparative importance of different causes and to identify their severity; the thirteen problems were arranged in rank order (Table 3). Among the major causes of labor migration "higher income possibilities" from other home and abroad sources ranked first. This might be due to the reason that in the rural areas there is lower payment rate than that of urban or abroad. This is because, in rural areas, there is no fixed rate of labor employment. So, the labor users give them minimum wages and exploit them for longer periods especially in dull season than urban areas. Again, laborers do not get any fixed work and wages. Because, most of the works in the rural areas are season specific, i.e. during the land preparation, seed sowing, intercultural operations, harvesting of crop there is huge demand of labors but the rest of the time there is scarcity of work. As a result, they don't get any job, become unemployed and have to suffer from severe starvation along with their family members, viz. children, old aged and women. Therefore, they have no alternatives but to migrate themselves in search of job.

Table 3. Rank order of the causes of labor migration in the study area

\begin{tabular}{rlcc}
\hline SL & Causes of migration & Assigned scores & Rank \\
\hline 1. & Higher income expectation & 233 & $1^{\text {st }}$ \\
2. & Job security & 199 & $2^{\text {nd }}$ \\
3. & Social status & 185 & $3^{\text {rd }}$ \\
4. & Positive information about the city & 119 & $4^{\text {th }}$ \\
5. & Law and order situation & 121 & $5^{\text {th }}$ \\
6. & Better health service & 115 & $6^{\text {th }}$ \\
7. & Hardship & 99 & $7^{\text {th }}$ \\
8. & Conflict & 95 & $8^{\text {th }}$ \\
9. & Family desire & 94 & $9^{\text {th }}$ \\
10. & Easy access to information sources & 91 & $10^{\text {th }}$ \\
\hline
\end{tabular}

Table 4. Current labor migration status in the study area (Based on group discussion, $n=45$ )

\begin{tabular}{|c|c|c|c|c|c|c|c|c|}
\hline & \multicolumn{3}{|c|}{ In country migration } & \multicolumn{4}{|c|}{ Abroad migration } & \multirow[b]{2}{*}{ Total } \\
\hline Villages & 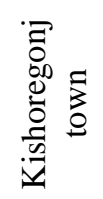 & 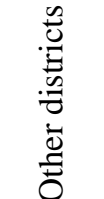 & 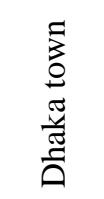 & 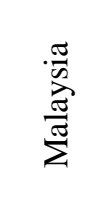 & 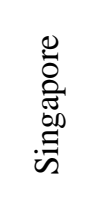 & 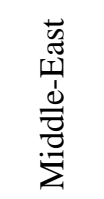 & 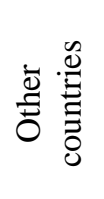 & \\
\hline Narandi & 5 & 15 & 120 & 84 & 21 & 264 & 21 & 530 \\
\hline Hossendi & 7 & 25 & 160 & 65 & 25 & 255 & 25 & 562 \\
\hline Patuabhanga & 6 & 32 & 130 & 55 & 48 & 225 & 30 & 526 \\
\hline Total & $\begin{array}{c}18 \\
\left(3.6^{*}\right)\end{array}$ & $\begin{array}{c}72 \\
(14.4)\end{array}$ & $\begin{array}{c}410 \\
(82.0)\end{array}$ & $\begin{array}{c}204 \\
(18.3)\end{array}$ & $\begin{array}{c}94 \\
(8.4)\end{array}$ & $\begin{array}{c}744 \\
(66.6)\end{array}$ & $\begin{array}{c}76 \\
(6.7)\end{array}$ & 1618 \\
\hline
\end{tabular}

*Number in parenthesis indicate percent 
Again, agricultural labors are always down trodden class in the rural areas. People are very callous about their dignity and these labors always remained as ignored in participating any social gatherings. Their children also have to suffer from the same in the rural areas. So, they migrate in the urban areas and engaged in works other than agriculture. Rural people traditionally, imagine that towns and cities are always full of jobs, better scope of getting jobs and other modern amenities. Therefore, being imbued from ambitious thinking of better lives, they migrate to the cities and towns. Current law and order situation of the rural areas also provoke rural youth to migrate themselves to urban areas. To keep them safe from any village factions and political rivalry they might also take this alternative of survival. The other important causes are "better health service", "hardship", "conflict", "family desire" and "easy access to information sources".

\subsubsection{Destination wise labor migration status}

Agricultural labors are migrated in different places viz. in the own district town, in other districts, in Dhaka city, in Middle East, Singapore, Malaysia and other Asian countries. Results shown in Table 4 indicate that the total number of migrants in the three villages is 1618 . Among them 30.8 percent are in country migrants and 69.2 percent are abroad migrants. Among the in-country migrants 3.6 percent located in Kishorgonj district town, 82.0 percent located in capital city, Dhaka and 14.4 percent located in other districts. Among the abroad migrants, larger part (66.6\%) located in Middle-
East followed by 18.3 percent in Malaysia, 8.4 percent located in Singapore, and 6.7 percent located in other countries. Among the abroad migrants most of them are located in MiddleEast due to their unskilled situation. Among the in-country migrants, most of them are located in capital city, Dhaka and engaged in Ready Made Garments (RMG) factories.

It was very clear from the discussion with the participants that migrants working in other districts are mostly engaged as seasonal agricultural labor. It means that when there is scarcity of job in the study area they migrated for sometimes in the adjacent or other districts in search of work. It is reported that a lot of the internal migration that takes place is driven by the seasonality in the agricultural labor demand (Afsar, 2003; Neelim and Siddiqui, 2015).

\subsubsection{Types of labor migration}

There are several types of migrants throughout the world. Luthra et al. (2018) reported six type migrants viz. traditional circular, short term accumulator, committed expat, living and learning, follower and adventurer. Woldeab (2019) in a study, classified migrants in four types, namely labor migration, force migration or displacement, human trafficking and modern slavery and environmental migration. However, the present research revealed six types of migration, viz. rural-urban, other country, seasonal migration, circular migration, conflict migration, and pressure migration. To identify their severity; the six types were arranged in rank order (Table 5).

Table 5. Rank order of types of labor migration from the respondents' family

\begin{tabular}{rlcc}
\hline SL & Category & Number & Rank \\
\hline 1. & From rural to urban & 40 & $1^{\text {st }}$ \\
2. & To other country & 40 & $1^{\text {nd }}$ \\
3. & Seasonal migration & 24 & $2^{\text {rd }}$ \\
4. & Circular migration & 14 & $3^{\text {th }}$ \\
5. & Conflict migration & 9 & $4^{\text {th }}$ \\
6. & Pressure migration & 6 & $5^{\text {th }}$ \\
\hline
\end{tabular}


Table 6. Rank order of impact of labor migration on agricultural production in the study area

\begin{tabular}{clcc}
\hline SL & Impact items & Index & Rank \\
\hline 1. & Decreased family labor & 226 & $1^{\text {st }}$ \\
2. & Remittance dependency & 215 & $2^{\text {nd }}$ \\
3. & Increased vulnerability to difficult situation & 187 & $3^{\text {rd }}$ \\
4. & Decreased agricultural land utilization & 181 & $4^{\text {th }}$ \\
5. & Decreased crop production & 173 & $5^{\text {th }}$ \\
6. & Food insecurity & 149 & $6^{\text {th }}$ \\
7. & Exploitation in labor availability & 108 & $7^{\text {th }}$ \\
8. & Inequality among rich and poor & 103 & $8^{\text {th }}$ \\
\hline
\end{tabular}

The most important form of migration evident from the discussion is rural-urban migration and migration to other country. Often, all of these six types of migration patterns are present in the study area. There are, however, an increasing number of women also participating in migration. The pattern of migration that occurs in the study area is usually indicative to its socioeconomic situation, and can, therefore, be seen as a very important phenomenon for development. These include: urbanization and manufacturing in urban area, more circulation within urban areas, and increased occupational diversification and mobility in response to macroeconomic reforms in study area. In Bangladesh, two-thirds of all migration is from rural to urban areas, and is increasing rapidly (Afshar, 2003).

\subsubsection{Labor migration and agricultural production}

FAO (2008) reported significant implications of migration on agriculture and rural development. Migration changes population distribution, gender-based discrimination, greater women's control over household resources and social organization in the rural areas. It influences pattern of agricultural production and consumption, credit distribution, household agricultural production, investment in agriculture, labor allocation decisions etc. Migration has neither led to agricultural abandonment nor have remittances been dedicated to agricultural improvements. Semi subsistence agriculture remains an important risk averse economic and cultural activity, but cultivation is a poor investment (Jokisch, 2002). In this study, respondent household owners identified different impacts of migration on agricultural production. In order to understand the comparative importance of different impacts, nine problems identified from the responses of the respondents were arranged in rank order (Table 6).

'Decreased family labor' was the top most concern of the respondents. Because, the end result of rural-urban migration is indicated by increasing labor shortage. The implication of this situation is reducing agricultural productivity in the study area. Most of the respondents agreed or strongly agreed that the movement of migrants away from the rural area decreased the labor availability for farm work. The long-term migration of farm labor has caused a grave concern in declining agricultural productivity. Long term migration to cities or elsewhere means that migrants are unwilling to return home and engage in agricultural activities and employment during the crop production season. The households with migrants have an average of agricultural income lower than households without migrants. Rozelle et al. (1999) also reported that rural urban migration occurs a serious and negative effect of loss of family labor on agricultural production. Household crop income is negatively affected by the loss of household labor (De Brauw and Rozelle, 2003).

Due to migration, the migrant families remain dependent on remittance and they become helpless when flow of remittance stops. This 
might be due to the reason that remittance dependent families rely on hired labor for performing agricultural operations. But, ceaseless flow of remittance may not be possible all the times because of a variety of reasons. Resultantly, they fall in difficult situation. Another vital impact of labor migration on agriculture is 'increased vulnerability to difficult situation'. This might be happened when any natural calamity occurs and there is very urgent to take any decision on crop production, viz. urgent sowing of seeds due to decreasing soil moisture, prompt decision to use any plant protection measure, quick irrigation of the crop field and urgent decision on harvesting of crops to avoid any natural damage. But, Mosse et al. (2002), reported that migration and remittances are associated with household consumption smoothing and reduction in vulnerability against unforeseen circumstances. Remittances enable income stability insuring against such incidences as seasonality of income earning, income losses due to draught, flood or death of family livestock (Mahmood, 2014).

Other major impacts of labor migrations on agriculture were: "decreased agricultural land utilization", "decreased crop production", “food insecurity", "exploitation" and "inequality among landless and poorest". Sapkota (2018), in a study reported that the income from agriculture constitutes less than 20.0 percent of its total income for migrant households and the origin of migrants are highly vulnerable to climate change due to poverty and dependence on climatesensitive livelihood.

\subsection{Impact of labor migration on rural livelihood}

Usually, there are some effects of migration in areas of origin. These are "remittance", "income", "decreased agricultural land", "decreased vegetation", "real properties", "competency", "gadget", "skills and technology transfer", "increased social network", "behavioral change" (Singh et al., 2012). In order to understand the comparative impact on the five livelihood capitals were arranged in
Table 7. Two components were considered for each capital to calculate rand order based on the respondents' response. The most important positive effect of migration is increase of financial capital. It gets robust from remittance which migrants send to their home and their income increases to some extent. Hence, migration of a household member is used as a means of income diversification against risks. Loss in yield due to the reduction in available labor by out-migration may be compensated for partly by remittances from the migrants which are used to purchase additional inputs or hire labor substitutes for cropping. In a study, Han (2014) reported that the households with migrants would consider some options for their future livelihood, and with enough resources accumulated through financial remittances of migrants and under appropriate socioeconomic conditions, they are very likely to pursue the new ways of living. Therefore, being rich in financial capital with successful migration would more likely to be associated with a high chance of a household to invest in agricultural activities rather than the opposite direction.

Natural capital involves environmental perceptions and the possession of land. Due to rural labor migration, natural capital, i.e. agricultural land shrinkages. Because, respondents sometimes become bound to quit some of their agricultural production and leave their land fallen vacant leading to decreased vegetation. It has a negative environmental impact also. This might be due to the reason that when respondents find labor shortage, they just quit themselves from agricultural production and look for other profitable off-farm activities. A poor environmental condition would make a household to stay away from agricultural activities and to consider other options, like finding a job in the non-farm sector (Han, 2014). Being in abroad, after several years when migrant workers return home, they usually build a relatively permanent house in their cultivable land. Sometimes they build infrastructure for business purposes in road side cultivable land. These situations cause loss of flora and fauna 
diversity for uncountable time leading decreased natural capital. Again, when the agricultural laborers go to other country, they sometimes sell their cultivable land to others which causes their personal decrease of natural capital.

Physical capital increase is very tangible results commonly observed in the rural labor migrant families. This might be because of receiving remittance the migrant families try to prove their improved socioeconomic position through addition of some assets, e.g. brick-built house, modern furniture, electrical and electronics daily essentials. During data collection, the researchers also directly observed that respondents who have migrants in their families possessed more physical assets than those who didn't have. Physical capital would moderate the relationship between migration and agricultural transition. Physical capital consists of housing quality, agricultural equipment and consumer items. Successful migration would encourage a household to keep investing in agriculture. When a household owns many consumer items, however, the household would be more likely to move away from agricultural activities and migration would hasten it (Han, 2014).

Migrants, due to be in urban town, cities and abroad, learn some skills which make them more competence than their village friends and fellows and they become the carrier of some technology transfer to the rural areas, e.g. western modern amenities. This leads them to improve their human capitals. Migration experience and remittance might drive some household members to pursue their career in the non-farm sector. Migration could work as a pathway to change the modes of production away from farming in the context of Albania (Miluka et al., 2010).

Table 7. Impact of labor migration on livelihood capitals of the respondents

\begin{tabular}{|c|c|c|c|c|}
\hline \multirow[b]{2}{*}{ Capitals } & \multirow[b]{2}{*}{ Impacts } & \multicolumn{2}{|c|}{ Assigned scores } & \multirow[b]{2}{*}{ Rank } \\
\hline & & $\begin{array}{l}\text { Component } \\
\text {-wise }\end{array}$ & Total & \\
\hline \multirow{2}{*}{ Human } & 1. Improved skills in agricultural practices & 112 & \multirow{2}{*}{261} & \multirow{2}{*}{$4^{\text {th }}$} \\
\hline & 2. Enhanced competency in managing farm production & 149 & & \\
\hline \multirow{2}{*}{ Physical } & 1. Enriched household gadgets & 116 & \multirow{2}{*}{287} & \multirow{2}{*}{$3^{\text {rd }}$} \\
\hline & 2. Enriched real properties possession & 171 & & \\
\hline \multirow{2}{*}{ Financial } & 1. Increased remittance flow & 226 & \multirow{2}{*}{450} & \multirow{2}{*}{$1^{\mathrm{st}}$} \\
\hline & 2. Increased total household income & 224 & & \\
\hline \multirow{2}{*}{ Social } & 1. Enhanced social relationship & 110 & \multirow{2}{*}{221} & \multirow{2}{*}{$5^{\text {th }}$} \\
\hline & 2. Developed social network & 111 & & \\
\hline \multirow{2}{*}{ Natural } & 1. Decreased agricultural land status & 186 & \multirow{2}{*}{369} & \multirow{2}{*}{$2^{\text {nd }}$} \\
\hline & 2. Reduced natural vegetation & 183 & & \\
\hline
\end{tabular}

Table 8. Measures taken by the respondent towards adjusting labor shortage

\begin{tabular}{clcc}
\hline Sl & Measures & Assigned scores & Rank \\
\hline 1. & Hiring labor & 225 & $1^{\text {st }}$ \\
2. & Change cropping pattern & 182 & $2^{\text {nd }}$ \\
3. & Agricultural transformation & 177 & $3^{\text {rd }}$ \\
4. & By increasing the wages of labor & 176 & $4^{\text {th }}$ \\
5. & By working with others & 137 & $5^{\text {th }}$ \\
6. & Reducing fragmented land & 118 & $6^{\text {th }}$ \\
7. & With the help of extended family & 81 & $7^{\text {th }}$ \\
\hline
\end{tabular}


Migrants tend to be economically active after they returned to their home countries and most of them worked in the non-farm sector, especially as entrepreneurs or salaried workers (Dustmann and Kirchkamp, 2001).

As the migrants live in the village, cities and towns of home and abroad they adopt some changes in their behavior due to induction effect. They might adapt themselves in the society with changing their behavioral pattern, i.e. they manage their difficult situations jointly due to absence of their near and dears. They also maintain increased social network with their home and abroad friends and well-wishers. In this way, they improve their social capital. According to Levitt (1998 and 2001), migration brings not only financial remittance, but also social remittances, such as experience, new ideas and thoughts. This implies that, besides money, what migrants have seen and experienced in migration destinations might have changed the way they looked at the world and could affect what they have been doing for living (Dabir et al., 2013).

\subsection{Measures taken towards minimizing labor shortage in agriculture}

Different measures have been adopted by the respondents to minimize labor shortage situations. These measures situation specific and respondents' socio-economic condition specific. From their opinions, these measures to minimize labor constraints in carrying out their agricultural activities were accumulated and categorized in to seven different classes as shown in Table 8 . Results indicate that the majority of the respondents who face labor constraints are able to overcome the situation by hiring labor from different sources to assist their farm operations. They usually hire labor from their nearby town point where labors wait for work. Impact of timely acquisition of labor positively affects the agricultural production.

Agricultural transformations another way of minimizing labor shortage. In this case, respondents select the labor extensive agricultural approach like establishment of fruit orchard, plantation of wood tree etc. instead of labor-intensive agricultural activities like vegetable cultivation, cereal crop cultivation and so on. Respondents also change cropping pattern, i.e. shift from labor intensive cropping pattern to labor extension one for adaptation of labor shortage situation. They sometimes put their land fallow, change the short durational type of crops with long durational crops. Increasing the wages of labors usually common scenario in the village to keep themselves with their traditional agricultural occupation. Respondents also adopt other mechanism like working with other respondents in a group, reducing cultivated area and sometimes think increase the number of working family member extending the size of the family.

\section{Conclusions}

Socio-economic features of the household owners reveal that majority of them fall under old age group; belonged to the group of primary level of education; had large family size; major part of family were nuclear had medium income category; greater part had medium contact with the sources of information having low organizational participation and high cosmopolite characteristics. In case of internal migration, migrant workers mainly migrate in Dhaka city but in case of abroad migration they migrate in Middle East. Major cause of labor migration is higher income possibility followed by job security, social status, positive information about city, law and order situation, better health service and hardship. Out of different types of migration rural-urban migration and migration to other country are the most dominant. Vital negative impact of labor migration on agricultural production is decreased family labor followed by remittance dependency and increased vulnerability, decreased agricultural land, decreased crop production and food insecurity. Important positive impact of migration on rural livelihood is on financial capital followed by physical, human and social capitals whereas negative impact is on natural 
capital. The household owners who faced labor constraints are able to overcome the situation by hiring labor to assist in their farm operations. Sometimes, they change cropping patterns for decreasing wages of labor, work with other respondents, and reduce fragmented land. Increased growth both in agriculture, since most rural workers earn their living from primary production; and the rural non-farm economy are important to consider side by side. Therefore, growth in agriculture will create some new jobs, first and foremost in the industrial forms of farming. Development or the intensification of the non-farm economy will be vital in creating new jobs and, consequently, putting increasing pressure on rural wages. Credit providing organizations may come forward to help respondents by providing financial support as soft loan at an easy terms and condition. Awareness raising campaign may be held by the concerned authority on the importance of natural capital as the source of agricultural production.

\section{References}

Afrad MSI. 2010. Adoption of arsenic mitigation options by the programs' beneficiaries. The Journal of Rural Development, 37(1):145-166.

Afsar R. 2003. Internal migration and the development nexus: the case of Bangladesh. Paper presented at the Migration, Development and Pro-Poor Policy Choices in Asia, 22-24 June, Dhaka, Refugee and Migratory Movements Research Unit and UK Department for International Development.

Afshar OA. 2003. Effects of rural-urban migration of youth on agricultural labour supply in Umea north local government area of Abita state, Nigeria. Journal of Agricultural Research, 3(2):77-83.

Agesa R, Kim S. 2001. Rural to urban migration as household decision: evidence from Kenya. Review of Development Economics, (5): 60-75.
Ahmed MB. 2003. Impact of shrimp farming on socio-economic, agriculture and environmental conditions in Paikgacha upazila of Khulna district. PhD Dissertation, Bangabandhu Sheikh Mujibur Rahman Agricultural University, Gazipur.

Ali H, Azad MAK, Anisuzzaman M, Chowdhury MMR, Haque M, Ariful MIS. 2009. Livelihood status of the fish respondents in some selected areas of Tarakanda upazila of Mymensingh district. Journal of Agroforestry and Environment, (3): 8589.

Ali MA. 2007. Impact of pineapple cultivation on the socio-economic condition of respondents. MS Thesis, Department of Agricultural Extension and Rural Development. Bangabandhu Sheikh Mujibur Rahman Agricultural University, Gazipur, Bangladesh.

Ali MS, Karim ASMZ, Kashem MA, Islam MM. 2008. Adoption of selected agricultural ecological practices by the respondents. Bangladesh Journal of Extension Education, 20 (1\&2): 54.

Aworemi JR, Abdul-Azeez IA, Opoola NA. 2011. An appraisal of the factors influencing rural-urban migration in some selected local government areas of Lagos State Nigeria. Journal of Sustainable Development, 4 (3): 136-141. DOI: 10.5539/jsd.v4n3p136

Dabir M, Daroudi I, Khazri MD. 2013. Impact of migration in economic and social of rural environments. International Research Journal of Applied and Basic Sciences, 7(5): 288-298.

De Brauw A, Rozelle S. 2003. Migration and household investment in rural China. University of California, Davis, Department of Agricultural and Resource Economics, Davis, CA, USA.

De Haas H. 2001. Migration and Agricultural Transformations in the Oases of Morocco and Tunisia. Utrecht: KNAG

Deshingkar P. 2004. Understanding the implications of migration for pro-poor 
agricultural growth. Paper presented at the DAC POVNET Agriculture Task Group Meeting, Helsinki, 17-18 June.

DFID. 1999. Sustainable Livelihoods Guidance Sheets. London: Department for International Development.

Dustmann C, Kirchkamp O. 2001.The optimal migration duration and activity choice after re-migration, Journal of Development Economics, 67(2):351-372.

FAO. 2008. migration, agriculture and rural development: a FAO perspective, available https://www.un.org/en/development/desa/ population/events/pdf/8/P08_FAO.pdf

Farhad AKU. 2008. Coping strategies practiced by the respondents against flood in Bangladesh. PhD Dissertation, Bangabandhu Sheikh Mujibur Rahman Agricultural University, Gazipur, Bangladesh.

Han SY. 2014. Migration and livelihood transitions of rural farming households. $P h D$ Dissertation, Arizona State University.

IFAD. 2007. International Fund for Agricultural Development. Sending money home, Rome, Italy http://www.ifad.org/events/remittances/m aps/brochure

Imran HA. 2011. Coping strategies practiced by displaces for river erosion. MS Thesis, Bangabandhu Sheikh Mujibur Rahman Agricultural University, Gazipur, Bangladesh.

Imran M, Bakhsg K, Hassan S. 2016. Rural to urban migration and crop productivity: evidence from Pakistani Punjab. Mediterranean Agricultural Sciences, 29(1): 17-19

Islam M. 2011. Perception of Sub assistant agriculture officer on sustainable agricultural practices. MS Thesis, Bangabandhu Sheikh Mujibur Rahman Agricultural University, Gazipur, Bangladesh.

Islam S, Parvin S, Kalam A. 2013. Socioeconomic impacts of international migration in Bangladesh. Journal of Economics and Sustainable Development, 4(4): 9-18.

Jokisch BD. 2002. Migration and agricultural change: the case of small holder in high land Ecuador. Human Ecology, 30(4): 523-550.

Kim CJ, Dumont JC, Boonpala P. 2018. Labor immigration in Asia increasing the development impact of migration through finance and technology. Asian Development Bank Institute (ADBI), the Organization for Economic Co-operation and Development (OECD), and the International Labor Organization (ILO).

Levitt P. 1998. Social remittances: migration driven local-level forms of cultural diffusion. International Migration Review, 32(4): 926-948.

Levitt P. 2001. The Transnational Villagers. Berkeley: University of California Press.

Luthra R, Platt L, Salamonska J. 2018. Types of migration: the motivations, composition, and early integration patterns of "new migrants" in Europe, International Migrant Review, 52(2):368-403, DOI: 10.1177/0197918318781586

Mahmood, RA. 2014. Differential impact of migration on poverty and wellbeing: evidence based on Bangladesh data. Paper presented at the Internal Migration and Urbanization Conference, Organized by KNOMAD, 30 April - 1 May 2014, Dhaka, Bangladesh.

Mc Catty M. 2004. The process of rural-urban migration in developing countries. Bachelor Thesis, Carleton University, Ottawa.

Miluka J., Carletto G., Davis B., Zezza A. 2010. The vanishing farms? The impact of international migration on Albanian family farming, The Journal of Development Studies, 46:1, 140161, DOI: 10.1080/00220380903197978

Mosse D, Gupta S, Mehta M, Shah V, Rees J. 2002. Brokered livelihoods: debt, labor migration and development in tribal 
Western India", Journal of Development Studies, 38(5): 59-87.

Neelim A, Siddiqui T. 2015. Situation analysis of migration context and policy framework in Bangladesh. The Refugee and Migratory Movements Research Unit, International Organization for Migration, IOM-UNDP Global Joint Program on 'Mainstreaming Migration into National Development Strategies' supported by Swiss Agency for Development and Cooperation (SDC).

Parvez AKMK. 2007. Respondents'knowledge, attitude and practices in using IPM. PAT 2008, 4(2): 1-11.

Patwary MA. 2018. Adoption of e-agriculture in transfer of agricultural information. $M S$ Thesis, Bangabandhu Sheikh Mujibur Rahman Agricultural University, Gazipur, Bangladesh.

Prodhan FA. 2012. Barriers and preparedness of Sub Assistant Agriculture Officers towards ICT utilization. MS Thesis, Bangabandhu Sheikh Mujibur Rahman Agricultural University, Gazipur, Bangladesh.

Rahman FMM. 2011. Hybrid rice cultivation and impact on social inequality in some selected areas of Bangladesh. PhD Dissertation, Bangabandhu Sheikh Mujibur Rahman Agricultural University. Gazipur, Bangladesh.

Regmi G, Tisdell C. 2002. Remitting behavior of Nepalese rural-to-urban migrants: implications for theory and policy. Journal of Development Studies, 38(3):76-94.

Rozelle S, Taylor JE, De Brauw A. 1999. Migration remittances, and agricultural Productivity in China. American Economic Review, 89 (2), 287-291.
Sapkota K. 2018. Seasonal labour migration and livelihood in the middle hill of Nepal: Reflections from Arghakhanchi District. Research Nepal Journal of Development Studies, 1(1): 42-57.

Siddiqui T, Sultana M, Sultana R, Akhter S. 2019. Labor migration from Bangladesh 2018 achievements and challenges. Refugee and Migratory Movements Research Unit (RMMRU).

Singh R., Singh KM., Jha A. 2012. Effect of Migration on Agricultural Productivity and Women Empowerment in Bihar (July 17, 2012). Available at SSRN: https://ssrn.com/abstract=2111155 or http://dx.doi.org/10.2139/ssrn.2111155

Stanat P, Christensen G. 2006. Where immigrant students succeed: a comparative review of performance and engagement in Pisa. OECD Publishing, $1^{\text {st }}$ Edition. Paris.

Sultana A. 2015. Knowledge of farm women on nutritional value of farm products, $M S$ Thesis, Bangabandhu Sheikh Mujibur Rahman agricultural University, Gazipur, Bangladesh.

Tuli AN. 2011. Women's participation in household and agricultural activities in selected area of Gazipur district. $M S$ Thesis, Bangabandhu Sheikh Mujibur Rahman agricultural University, Gazipur, Bangladesh.

UNESCO.

2018.

Dhakatribune.com/Bangladesh/education/ 2018/03/21/unesco bangladesh-literacyrate-reaches-time-high-72-76.

Woldeab R. 2019. Why Do People Migrate? The 4 Most Common Types of Migration. PopEd Blog. Available at: https://populationeducation.org/why-dopeople-migrate-the-4-most-commontypes-of-migration/ 